\title{
Electrodeposition and Characterization of Nanocrystalline Ni-Mo Catalysts for Hydrogen Production
}

\author{
J. Halim, ${ }^{1}$ R. Abdel-Karim, ${ }^{1}$ S. El-Raghy, ${ }^{1}$ M. Nabil, ${ }^{1}$ and A. Waheed ${ }^{2}$ \\ ${ }^{1}$ Department of Metallurgy, Faculty of Engineering, Cairo University, Giza 12613, Egypt \\ ${ }^{2}$ Department of Metallurgy, Nuclear Research Center, Anshas, Cairo 13759, Egypt \\ Correspondence should be addressed to R. Abdel-Karim, randaabdelkarim@gmail.com
}

Received 27 September 2011; Revised 3 December 2011; Accepted 3 December 2011

Academic Editor: Fathallah Karimzadeh

Copyright $(2012$ J. Halim et al. This is an open access article distributed under the Creative Commons Attribution License, which permits unrestricted use, distribution, and reproduction in any medium, provided the original work is properly cited.

\begin{abstract}
Ni-Mo nanocrystalline deposits $(7-43 \mathrm{~nm})$ with a nodular morphology were prepared by electrodeposition using direct current from citrate-ammonia solutions. They exhibited a single Ni-Mo solid solution phase. The size of the nodules increased as electroplating current density increased. The molybdenum content-estimated using EDX analysis-in the deposits decreased from about 31 to $11 \mathrm{wt} \%$ as the current density increased from 5 to $80 \mathrm{~mA} \cdot \mathrm{cm}^{-2}$. The highest microhardness value $(285 \mathrm{Hv})$ corresponded to nanodeposits with $23 \%$ Mo. The highest corrosion resistance accompanied by relatively high hardness was detected for electrodeposits containing 15\% Mo. Mo content values between 11 and 15\% are recommended for obtaining better electrocatalytic activity for HER.
\end{abstract}

\section{Introduction}

Ni-Mo deposits have been well known for their use as cathodes for hydrogen production from water by electrolysis as well as catalysts for hydrogen production by steam reforming of hydrocarbons [1].

Arul Raj and Venkatesan [2] showed an increased electrocatalytic effect of Ni-Mo electrodeposited alloys for the hydrogen evolution reaction than that showed by nickel and other nickel-based binary alloys such as Ni-Co, Ni-W, Ni-Fe, and $\mathrm{Ni}-\mathrm{Cr}$. In addition, Ni-Mo alloys are considered as highly corrosion resistant due to the good corrosion protection characteristics of molybdenum in nonoxidizing solutions of hydrochloric, phosphoric, and hydrofluoric acid at most concentrations and temperatures and in boiling sulfuric acid up to about $60 \%$ concentration [3]. The nickel-molybdenum alloys normally containing $26-35 \mathrm{wt} \%$ Mo are among the few metallic materials that are resistant to corrosion by hydrochloric acid at all concentrations and temperatures [4].

RF magnetron sputtering, mechanical alloying, and electrodeposition techniques are employed in the production of nanocrystalline Ni-Mo alloys. Huang et al. [5] reported that these alloys prepared by RF magnetron sputtering technique were to be promising electrodes for hydrogen evolution reactions. Nanocrystalline Ni-Mo alloys have been successfully produced using mechanical alloying method according to Kedzierzawski et al. [6], indicating the positive contribution of the large surface area in increasing the catalytic effect as electrodes for hydrogen production and decreasing the exchange current density.

Electrodeposition is one of the most promising techniques for producing nanostructure materials owing to its relative low cost compared to the other methods. Electrodeposition produces nanocrystalline materials when the deposition parameters (e.g., plating bath composition, $\mathrm{pH}$, temperature, current density, etc.) are optimized such that electrocrystallization results in massive nucleation and reduced grain growth $[7,8]$. Due to better anticorrosive in several aggressive environments, mechanical and thermal stability characteristics of $\mathrm{Ni}-\mathrm{Mo}$ alloys, the electrodeposition of these alloys plays an important role. It is an example of the induced codeposition mechanism [9].

With the aim of describing the Ni-Mo electrodeposition mechanism, many investigations have been carried out and several hypotheses have been proposed. Clark et al. [8] have proposed a Ni-Mo electrodeposition mechanism based on a gradually (step by step) molybdate reduction to Mo (IV) oxide by $\mathrm{Ni}$ (II) species forming $\mathrm{MoO}_{2} \mathrm{Ni}_{4}$ that further is 
TABLE 1: Chemical composition of steel substrate, $w \mathrm{t} \%$.

\begin{tabular}{ccccccccc}
\hline$\% \mathrm{C}$ & $\% \mathrm{P}$ & $\% \mathrm{~S}$ & $\% \mathrm{Mn}$ & $\% \mathrm{Ni}$ & $\% \mathrm{Cr}$ & $\% \mathrm{~V}$ & $\% \mathrm{Cu}$ & $\% \mathrm{Fe}$ \\
\hline 0.051 & 0.017 & 0.0155 & 0.263 & 0.0311 & 0.0311 & 0.0058 & 0.006 & $\mathrm{rem}$.
\end{tabular}

reduced to forming Ni-Mo alloy, whereas, Podlaha and Landolt $[10,11]$ have proposed a model based on adsorption and catalytic reduction of molybdate species using a bath containing citrate species. They suggested a new surfaceadsorbed intermediate, $\left[\mathrm{Ni} \text { (II) } \mathrm{HCit}-\mathrm{MoO}_{2}\right]_{\mathrm{ads}}$. The deposition of Mo, as indicated by this model, is only possible when Ni (II) ions are present, while nickel ions reduction is following an independent path.

Ni-Mo alloys have been successfully electrodeposited by Arul Raj and Venkatesan [2] from citrate bath ( $\mathrm{pH} 10.5$ ). Sanches et al. [12] have investigated the deposition of NiMo alloys from citrate bath ( $\mathrm{pH} 4)$. The deposition of Ni-Mo alloys from another plating bath pyrophosphate-ammonium chloride ( $\mathrm{pH}$ 8.5) has been performed by Donten et al. [13].

Only a few papers were devoted to the morphological and phase characterization of Ni-Mo nanodeposits. Also the stability of such deposits in strongly alkaline media is of great importance [14].

The aim of this paper is the electrodeposition and physical-chemical characterization of nanocrystalline Ni-Mo alloys. The effect of changing the plating current density on the morphology, chemical composition, mechanical, corrosion, and electrochemical properties of deposited layers will be studied.

\section{Experimental Techniques}

The Ni-Mo coatings were deposited on $2 \mathrm{~cm} \times 2 \mathrm{~cm} \times$ $0.07 \mathrm{~cm}$ steel coupons delivered from Clas Ohlson, Sweden. The chemical composition of these coupons is presented in Table 1. They were subjected to grinding up to grit 1000 and polishing using silica suspension, this was followed by ultrasonic cleaning in acetone and after that in ethanol for 10 minutes each. The coupons were then degreased using a solution containing $30 \mathrm{~g} /$ liter of sodium carbonate $\left(\mathrm{Na}_{2} \mathrm{CO}_{3}\right)$ and $30 \mathrm{~g} /$ liter of sodium triphosphate $\left(\mathrm{Na}_{5} \mathrm{P}_{3} \mathrm{O}_{10}\right)$. Finally, an acid pickling treatment was performed by dipping the samples in $75 \%$ conc. $\mathrm{HCl}$ to remove any oxide particles or scale, at room temperature. The other side of the coupons was covered with nonconducting, chemically resistant adhesive.

The anode was made of $5 \mathrm{~cm} \times 5 \mathrm{~cm} \times 0.635 \mathrm{~cm}$ nickel plate (99.5\% Ni) supplied by Alfa Aesar, Germany. The anode and the cathode were connected to a source of electricity as positive and negative poles, respectively.

Based on previous work of Chassaing et al. [15], the samples were electroplated using an electrolytic bath containing hydrated nickel sulfate, sodium molybdenum, and sodium citrate (Table 2). All the salts used were supplied from Sigma Aldrich, Sweden. The temperature was $298 \mathrm{~K}$, and the $\mathrm{pH}$ of the bath was 9.5.

During deposition process, the bath was mechanically stirred (350 rpm), using a magnetic stirrer. Different plating current densities have been applied, namely, 5, 10, 20, 40, and $80 \mathrm{~mA} / \mathrm{cm}^{2}$, with total quantity of charge $(\mathrm{Q})=50 \mathrm{C} / \mathrm{cm}^{2}$.
TABLE 2: Composition of solution and working conditions of electroplating process for Ni-Mo nanodeposits.

\begin{tabular}{|c|c|c|c|c|c|c|}
\hline \multirow{2}{*}{\multicolumn{2}{|c|}{ Composition and working conditions }} & \multicolumn{5}{|c|}{ Test samples } \\
\hline & & 1 & 2 & 3 & 4 & 5 \\
\hline \multirow{4}{*}{ Composition } & $\mathrm{NiSO}_{4} \cdot 6 \mathrm{H}_{2} \mathrm{O}(\mathrm{mol} / \mathrm{L})$ & \multicolumn{5}{|c|}{0.2} \\
\hline & $\mathrm{Na}_{3} \mathrm{C}_{6} \mathrm{H}_{5} \mathrm{O}_{7} \cdot 2 \mathrm{H}_{2} \mathrm{O}(\mathrm{mol} / \mathrm{L})$ & \multicolumn{5}{|c|}{0.3} \\
\hline & $\mathrm{Na}_{2} \mathrm{MoO}_{4}(\mathrm{~mol} / \mathrm{L})$ & \multicolumn{5}{|c|}{0.02} \\
\hline & Ammonia solution & \multicolumn{5}{|c|}{ Excess } \\
\hline \multirow{6}{*}{ Conditions } & $\mathrm{pH}$ & \multicolumn{5}{|c|}{9.5} \\
\hline & Current density $\left(\mathrm{mA} / \mathrm{cm}^{2}\right)$ & \multicolumn{5}{|c|}{$5,10,20,40,80$} \\
\hline & Quantity of charge $\left(\mathrm{C} / \mathrm{cm}^{2}\right)$ & \multicolumn{5}{|c|}{50} \\
\hline & Time (minutes) & 167 & 83 & 42 & 21 & 11 \\
\hline & Speed (rpm) & \multicolumn{5}{|c|}{$350 \pm 5$} \\
\hline & Temperature $\left({ }^{\circ} \mathrm{C}\right)$ & \multicolumn{5}{|c|}{$25 \pm 1$} \\
\hline
\end{tabular}

Microstructure and phases morphology have been investigated by SEM (ULTRA 55, Zeiss) field emission, while the chemical analysis has been determined by EDX unit connected to the SEM. X-ray diffraction (XRD) technique with a copper anode $(\mathrm{k} \alpha=1.54059 \AA)$ was employed to identify the type of phases presented. A voltage of $45 \mathrm{KV}$ and a current of $35 \mathrm{~A}$ were applied in XRD unit. The numerical procedures were facilitated by using the computer software PANalytical X'Pert Highscore Plus. The crystalline size (D) was calculated by applying the Scherrer equation.

Microhardness test was conducted using microhardness tester machine (Shimadzu Hardness tester HMV-2T) with a load of $1.9 \mathrm{~N}$. The roughness measurements $(\mathrm{Rq})$ were performed using MITUTOYO surftest 301 device, with a percentage of error equal to $\pm 10 \%$.

Potentiodynamic polarization measurements were conducted using a standard three-electrode cell with the coated samples as working electrode, Pt as auxiliary electrode, and saturated calomel electrode as reference electrode. Only $0.2 \mathrm{~cm}^{2}$ of the Ni-Mo samples surface was subjected to $0.5 \mathrm{M}$ $\mathrm{NaOH}$ electrolyte at $25^{\circ} \mathrm{C}$.

This cell was connected to Voltalab 10 (PGZ100) device working at scanning rate $0.5 \mathrm{mV} / \mathrm{sec}$ and at scanning range from -1000 to $-100 \mathrm{mV}$. Corrosion rate $(\mathrm{mm} / \mathrm{y})$, corrosion potential $E_{\text {corr }}(\mathrm{mV})$, and Tafel slope were calculated using Tafel extrapolation technique offered by Volta Master 4 software.

The electrocatalytic behavior of Ni-Mo nanocrystalline electrodeposited alloys, for hydrogen evolution reaction (HER), has been evaluated by two methods. The first method [14] is the comparison of the potential of different Ni-Mo electrodeposited nanocrystalline alloys recorded at constant current density of $-0.04 \mathrm{~mA} / \mathrm{cm}^{2}$ in linear polarization curves $(I-V)$. The second method [16] is the comparison of the slope of the cathodic region of Tafel polarization curves ( $\beta$ cathodic).

\section{Results}

3.1. Microstructure Analysis. SEM micrographs represented in Figure 1 illustrate different morphologies of Ni-Mo alloys 


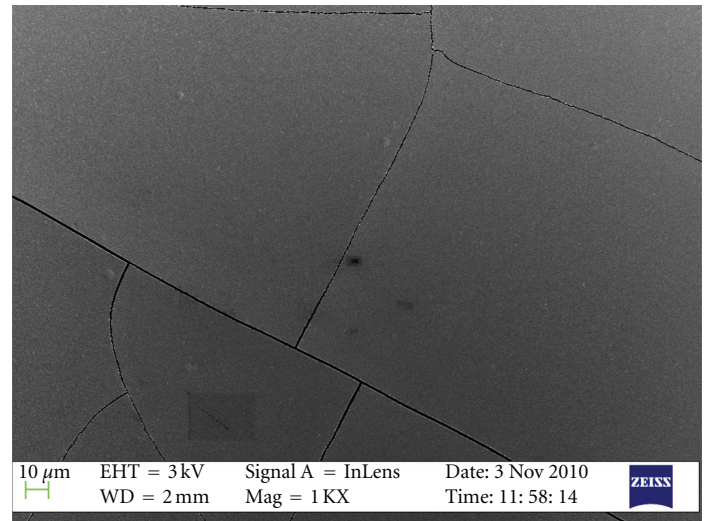

(a) $5 \mathrm{~mA} / \mathrm{cm}^{2}$ (low mag $1 \mathrm{Kx}$ )

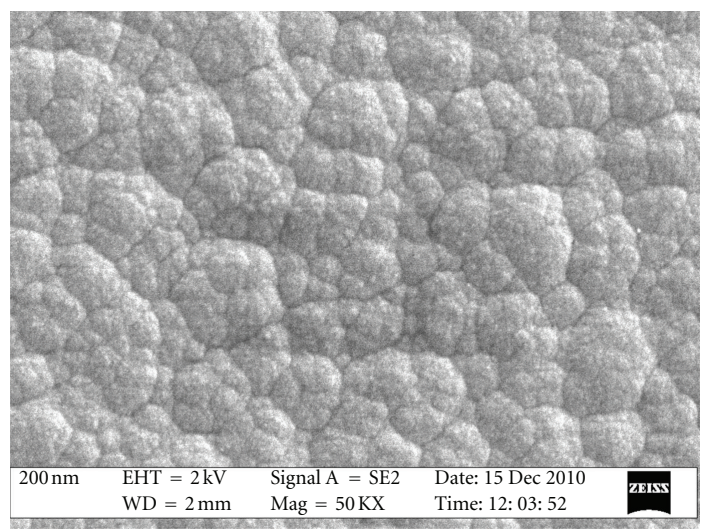

(c) $20 \mathrm{~mA} / \mathrm{cm}^{2}$

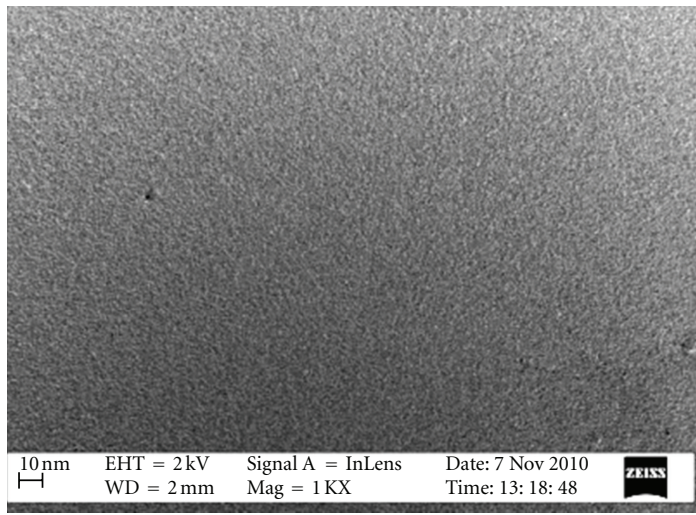

(e) $80 \mathrm{~mA} / \mathrm{cm}^{2}$ (low mag $1 \mathrm{Kx}$ )

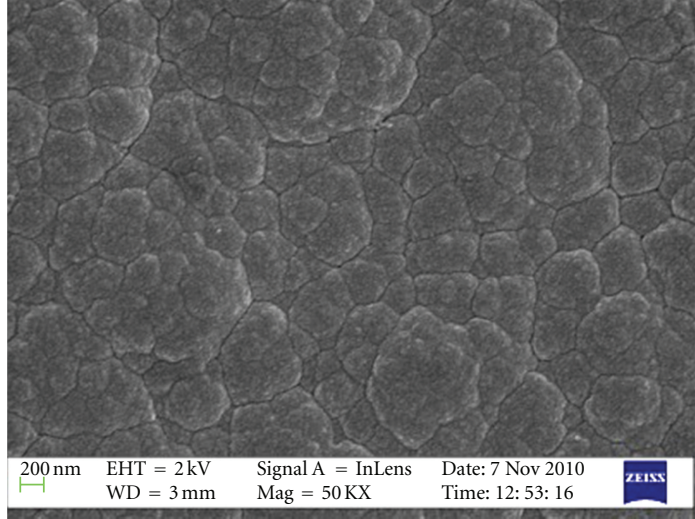

(b) $10 \mathrm{~mA} / \mathrm{cm}^{2}$

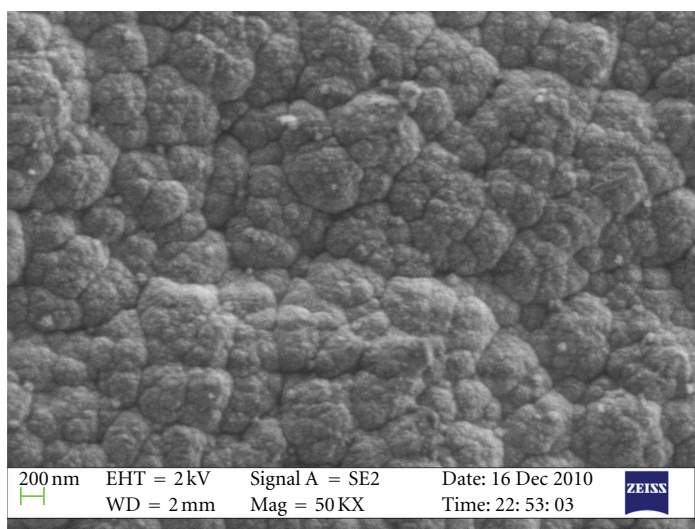

(d) $40 \mathrm{~mA} / \mathrm{cm}^{2}$

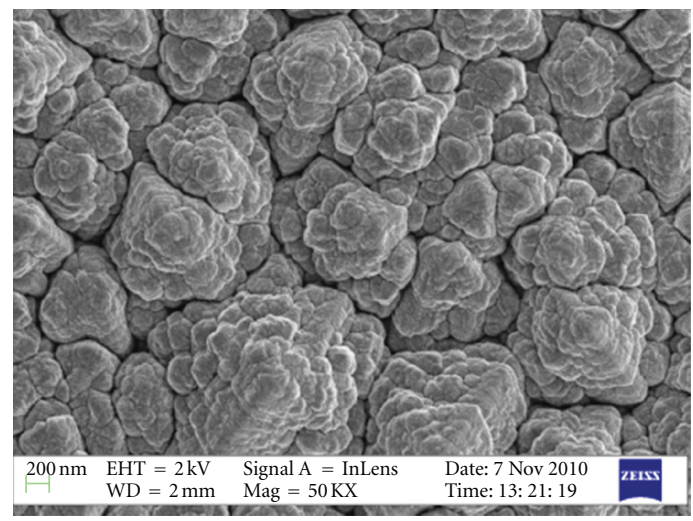

(f) $80 \mathrm{~mA} / \mathrm{cm}^{2}$

FIGURE 1: SEM micrographs of Ni-Mo nanocrystalline electrodeposits.

being electrodeposited on steel substrates depending on current densities. The SEM micrograph (Figure 1(a)) taken at low magnification $(1 \mathrm{Kx})$ of samples deposited at current density of $5 \mathrm{~mA} / \mathrm{cm}^{2}$ showed the existence of microcracks.

Generally, the obtained layers were characterized by a nodular morphology. In addition fine particles embedded in larger nodules and grain boundaries could be easily identified. The size of the nodules was dependent on the applied plating current density. The size of the nodules became coarser as electroplating current density increased as shown in Figures 1(b), 1(c), and 1(d), taken at high magnification
$(50 \mathrm{Kx})$. Figures $1(\mathrm{e})$ and $1(\mathrm{f})$ represent a highly rough surface morphology for Ni-Mo nanolayers electrodeposited using a current density of $80 \mathrm{~mA} / \mathrm{cm}^{2}$, at low (1 Kx) and high $(50 \mathrm{Kx})$ magnifications, respectively.

Cross-section SEM investigations (Figure 2(a)) confirmed the formation of cracked surface for Ni-Mo nanodeposits prepared using a current density of $80 \mathrm{~mA} / \mathrm{cm}^{2}$ and containing 31\% Mo. Meanwhile, homogeneous, compact, and crack-free deposits were detected for lower Mo contents. Figure 2(b) reveals cross-section SEM for Ni-Mo deposits containing $11 \% \mathrm{Mo}$, where no cracks were detected. 


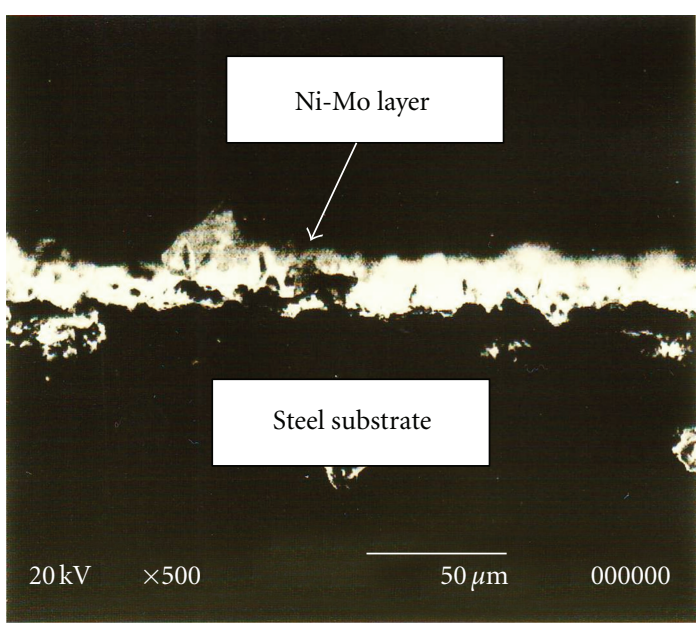

(a) $31 \% \mathrm{Mo}$

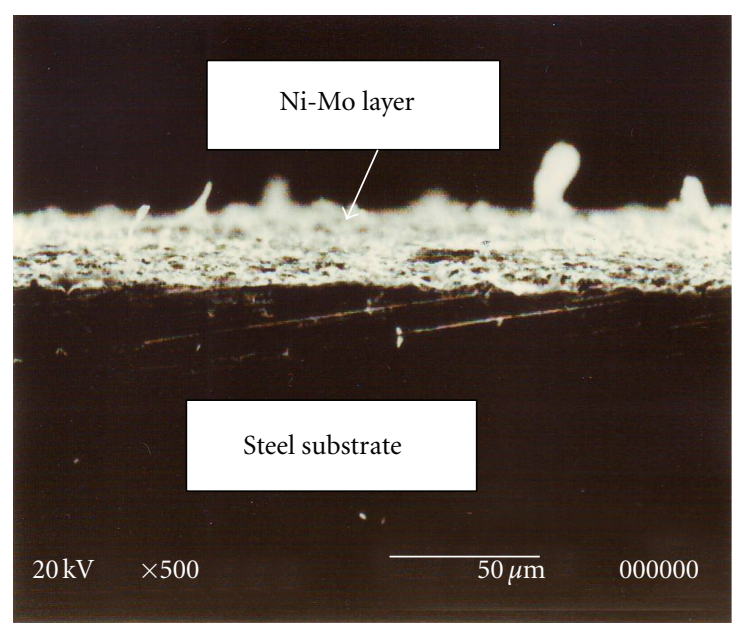

(b) $11 \% \mathrm{Mo}$

FIGURE 2: Cross-section morphologies of some Ni-Mo nanocrystalline electrodeposits.

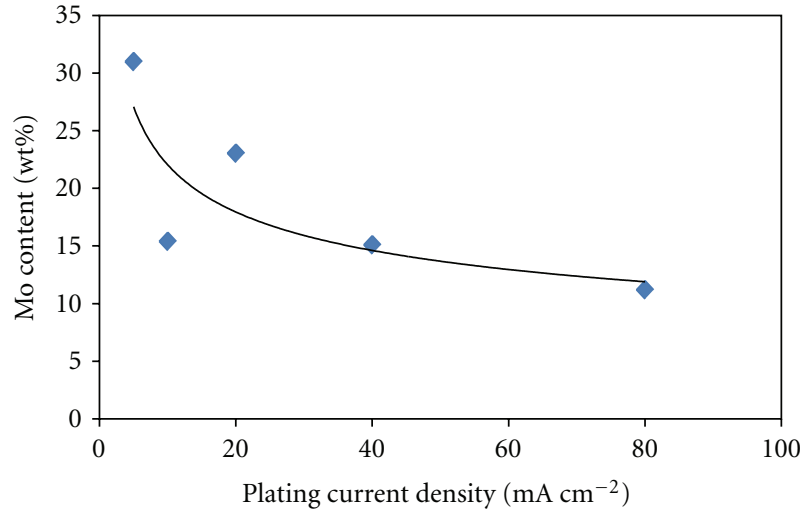

Figure 3: Molybdenum content of Ni-Mo nanocrystalline electrodeposits as a function of applied electroplating current density.

3.2. EDX Analysis. The chemical analysis of Ni-Mo alloys electrodeposited by various applied current densities was carried out by EDX using area analysis. There was a strong influence of the current density on the molybdenum content obtained in such deposits. From Figure 3, by increasing the current density from 5 to $80 \mathrm{~mA} / \mathrm{cm}^{2}$, the molybdenum content in the deposits was reduced from about 31 to $11 \mathrm{wt} \%$.

3.3. XRD Characterization. XRD technique was applied to determine the phases presented in the electrodeposited films as well as their crystallite size. According to literature [1719], the characteristic diffraction peaks for the face-centeredcubic Ni-Mo solid solution phase are at $2 \theta=43-44^{\circ}, 51^{\circ}, 74-$ $75^{\circ}, 92-93^{\circ}$, and $97-98^{\circ}$, which corresponds to the following planes: (111), (200), (202), (311), and (222), respectively.

Figure 4 showed that the $43-44^{\circ}$ peak was the common one for all samples. This indicates that all the electrodeposited Ni-Mo films were composed of one-phase Ni-Mo solid solution of face-centered-cubic structure.

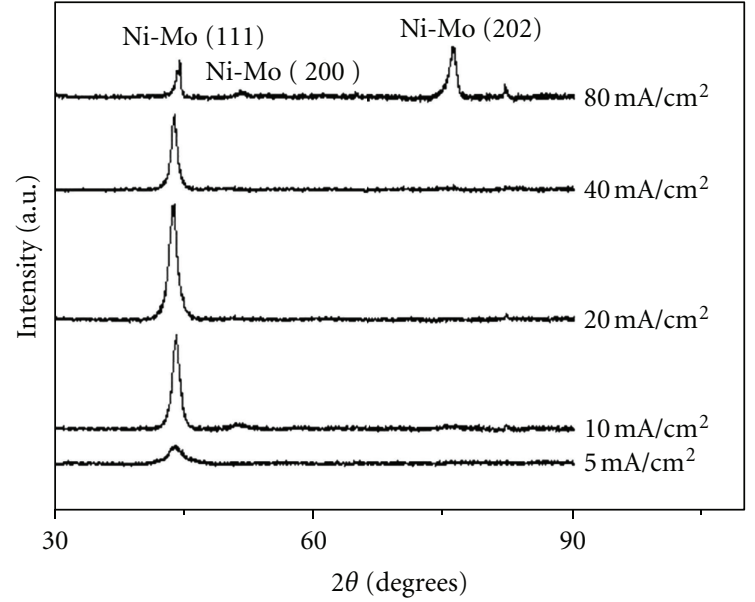

FIGURE 4: XRD pattern for Ni-Mo nanocrystalline electrodeposits at different current densities.

For the films being deposited at low current density, XRD diffraction lines were increasingly broadened and their intensities decreased, whereas the (111) preferred orientation became more pronounced. This indicated that by decreasing the plating current density, the degree of crystallinity decreased and the films exhibited a quasiamorphous structure. The diffraction patterns were wide at high content of Mo (31\%), while being sharp at the lowest content of Mo (11\%). In addition, the peaks corresponding to the planes (202) and (200) appeared indicating increasing the degree of anisotropy by decreasing Mo content from 31 to $11 \% \mathrm{Mo}$, with the (220) line being the most intensive.

The crystallite size, or more precisely the size of the coherent domains, was calculated from the line broadening using the Scherrer equation. Figure 5 illustrates the crystallite size of Ni-Mo electrodeposits as a function of the plating current density. The crystallite size increased from $\sim 7$ to 


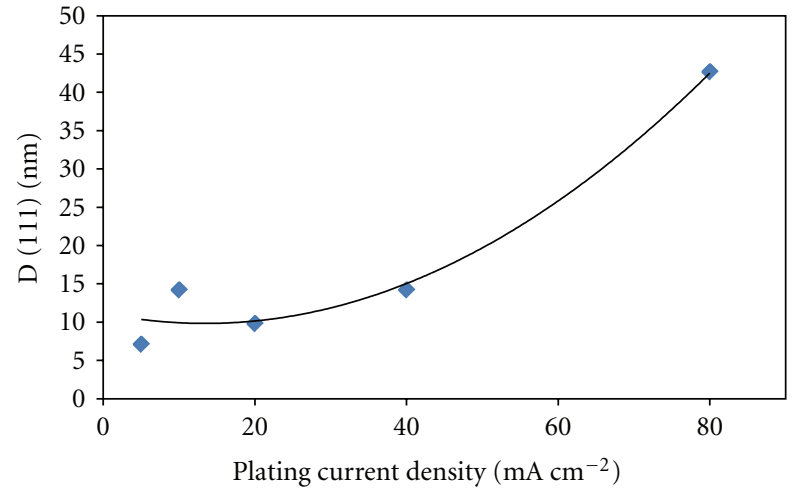

FIGURE 5: Crystallite size (coherency length along, $\langle 111\rangle$ direction) of nanocrystalline Ni-Mo electrodeposits as a function of current density.

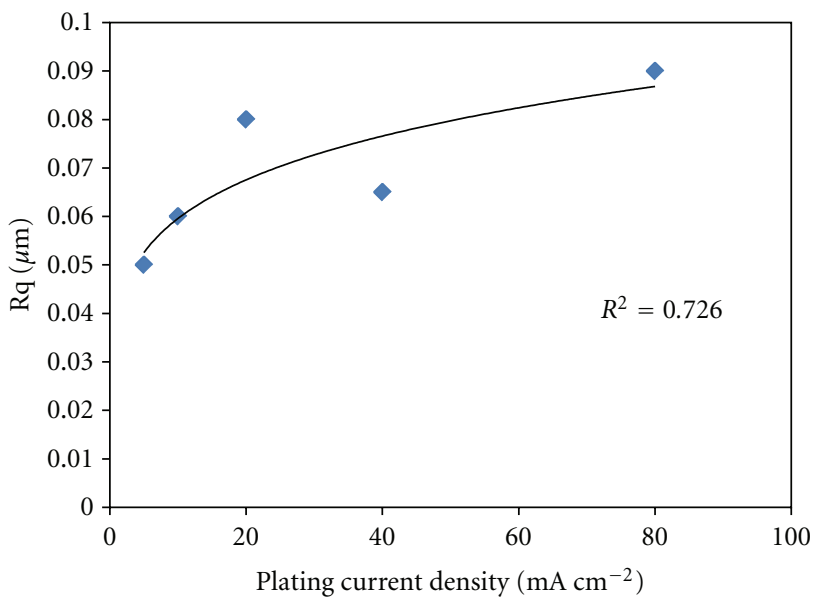

FIGURE 6: Surface roughness of Ni-Mo nanocrystalline electrodeposits as a function of plating current density.

$\sim 43 \mathrm{~nm}$ as the plating current density increased from 5 to $80 \mathrm{~mA} / \mathrm{cm}^{2}$.

3.4. Roughness Measurements. The roughness (Rq) of Ni-Mo deposits proved to be dependent on the current density, as shown in Figure 6. The roughness values increased from 0.05 to $0.09 \mu \mathrm{m}$ as a result of increasing the plating current density from 5 to $80 \mathrm{~mA} / \mathrm{cm}^{2}$. There was about $80 \%$ increase in the roughness values of $\mathrm{Ni}$-Mo electrodeposited nanocrystalline alloys, as the crystallite size increased from $\sim 7$ to $\sim 43 \mathrm{~nm}$.

3.5. Microhardness Measurements. The microhardness values obtained at load $1.9 \mathrm{~N}$ for $\mathrm{Ni}-\mathrm{Mo}$ nanodeposits are illustrated in Figure 7 as a function of crystallite size as well as molybdenum content. There was an increase in the microhardness of Ni-Mo alloys along with increasing the molybdenum content of the alloy. The maximum hardness (285VHN) was registered at Mo content of $23 \mathrm{wt} \%$. This was followed by a decrease in the microhardness from 285 to $175 \mathrm{HVN}$ as the molybdenum content was further increased reaching $31 \mathrm{wt} \%$.

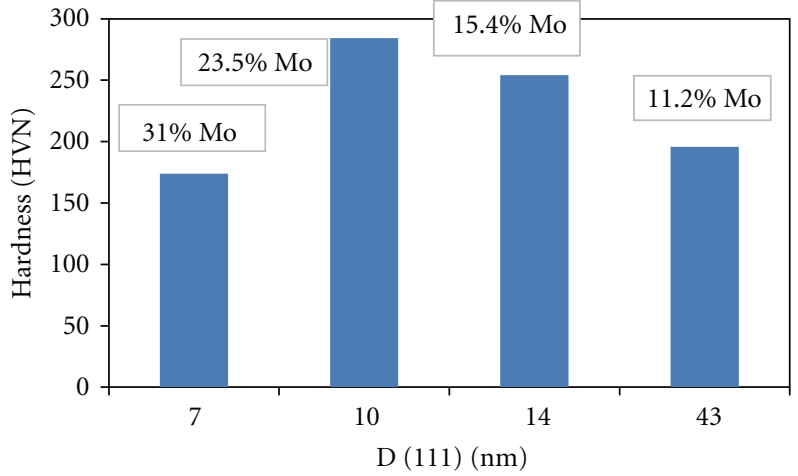

Figure 7: Microhardness of Ni-Mo nanocrystalline electrodeposited alloys as a function of molybdenum content as well as crystallite size.

TABLE 3: Corrosion properties of Ni-Mo nanocrystalline electrodeposites for different plating current densities compared to that of steel substrate examined in $0.5 \mathrm{M} \mathrm{NaOH}$ solution.

\begin{tabular}{lcccc}
\hline $\begin{array}{l}\text { Plating current } \\
\begin{array}{l}\text { density } \\
\left(\mathrm{mA} / \mathrm{cm}^{2}\right)\end{array}\end{array}$ & $\begin{array}{c}\text { Mo } \\
\text { content } \\
(\mathrm{wt} \%)\end{array}$ & $E_{\text {corr }}(\mathrm{mV})$ & $\begin{array}{c}I_{\text {corr }} \\
\left(\mathrm{mA} / \mathrm{cm}^{2}\right)\end{array}$ & $\begin{array}{c}\text { Corrosion } \\
\text { rate }\left(\times 10^{-3}\right. \\
\mathrm{mm} / \mathrm{y})\end{array}$ \\
\hline 5 & 31 & -294.2 & 6.93 & 81.1 \\
20 & 23 & -429 & 0.493 & 5.69 \\
40 & 15 & -473.3 & 0.4062 & 4.751 \\
80 & 11 & -434.7 & 0.7075 & 8.275 \\
\hline \multicolumn{2}{c}{ Steel substrate } & -1033.5 & 15.164 & 177.3 \\
\hline
\end{tabular}

Concerning the effect of crystallite size of these alloys, initially the micro-hardness values increased as the crystallite size of Ni-Mo alloys decreased from $\sim 43$ to $\sim 10 \mathrm{~nm}$. This was followed by a softening effect in the microhardness values by further crystallite size reduction down to $\sim 7 \mathrm{~nm}$.

3.6. Corrosion Behavior. The polarization curves for nanocrystalline electrodeposited Ni-Mo alloys with different molybdenum contents in a solution of $0.5 \mathrm{M} \mathrm{NaOH}$ are shown in Figure 8. The corrosion properties (corrosion current, corrosion potential, and corrosion rate) are summarized in Table 3.

The corrosion behaviour for Ni-Mo nanocrystalline alloys was dependent on two contradicting factors, namely, the molybdenum content and the grain size. The maximum corrosion rate $\left(81.1 \times 10^{-3} \mathrm{~mm} / \mathrm{y}\right)$ was obtained for deposits containing $31 \mathrm{wt} \%$ Mo. This observation was confirmed by SEM micrograph of that alloy after corrosion (Figure 9(a)), where the surface was highly corroded.

The minimum corrosion rate was $4.751 \times 10^{-3} \mathrm{~mm} / \mathrm{y}$ for the Ni-Mo nanocrystalline alloy containing $15 \mathrm{wt} \% \mathrm{Mo}$, having crystallite size of $14 \mathrm{~nm}$. The corresponding SEM micrograph of this alloy did not show any corrosion product or deterioration in its surface as shown in Figure 9(c).

An increase in the corrosion rate $\left(8.275 \times 10^{-3} \mathrm{~mm} / \mathrm{y}\right)$ was registered by further decreasing the Mo content down to $11 \%$ Mo. This trend was also observed in the SEM 


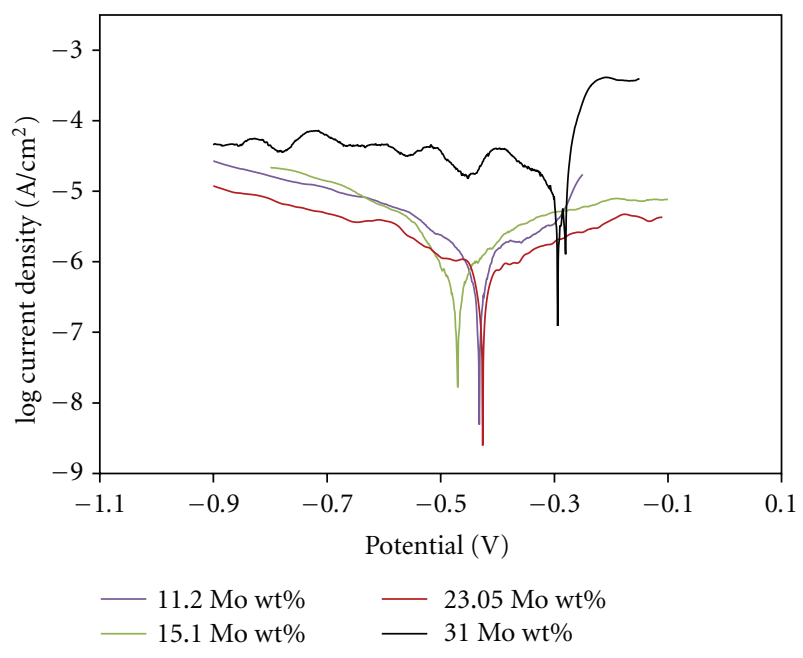

Figure 8: Polarization curves in semilogarithmic coordinates for nanocrystalline Ni-Mo electrodeposits examined in $0.5 \mathrm{M} \mathrm{NaOH}$ solution.

TABLE 4: Electrocatalytic properties of Ni-Mo nanocrystalline electrodeposits as a function of Mo content, roughness as well as crystallite size.

\begin{tabular}{lcccc}
\hline $\begin{array}{l}\text { Molybdenum } \\
\text { content (wt\%) }\end{array}$ & $\begin{array}{c}\text { Roughness } \\
\mathrm{Rq}(\mu \mathrm{m})\end{array}$ & $\begin{array}{c}\text { Ni-Mo } \\
\text { crystallite } \\
\text { size }(\mathrm{nm})\end{array}$ & $\begin{array}{c}\beta \text { Cathodic } \\
(\mathrm{mV} / \mathrm{dec})\end{array}$ & $\begin{array}{c}E \text { versus SCE } \\
(\mathrm{V}) \text { at } j= \\
-0.04 \mathrm{~mA} / \mathrm{cm}^{2}\end{array}$ \\
\hline 11 & 0.09 & 43 & 115 & -0.945 \\
15 & 0.065 & 14 & 79 & -0.967 \\
23 & 0.08 & 10 & 90 & -1 \\
\hline
\end{tabular}

micrograph of Ni-Mo electrodeposits after corrosion, shown in Figure 9(d).

3.7. Electrocatalytic Behavior. The electrocatalytic activity of $\mathrm{Ni}$-Mo nanocrystalline electrodeposits for hydrogen production has been evaluated by two methods. The first method [14] is the comparison of the potential of different $\mathrm{Ni}-\mathrm{Mo}$ electrodeposited nanocrystalline alloys recorded at constant current density of $-0.04 \mathrm{~mA} / \mathrm{cm}^{2}$ in polarization curves ( $I$ $V)$ shown in Figure 10. The second method [16] is the comparison of the Tafel slope of the cathodic region of polarization curves ( $\beta$ cathodic) for the different $\mathrm{Ni}-\mathrm{Mo}$ nanocrystalline electrodeposited alloys (Table 4).

According to Table 4, the potential results (recorded at a current density of $-0.04 \mathrm{~mA} / \mathrm{cm}^{2}$ ) showed that the minimum potential value was registered for the deposits with the highest surface roughness value $(0.09 \mu \mathrm{m})$. Mo content values between 11 and $15 \%$ are recommended for obtaining low potential values and thus better electrocatalytic activity for HER.

The influence of the molybdenum content as well as the surface roughness for Ni-Mo nanocrystalline electrodeposited alloys on $\beta$ cathodic values is clearly significant. By increasing the Mo content up to $15 \%$, the value of $\beta$ cathodic slope was reduced down to $79 \mathrm{mV} / \mathrm{dec}$ and an increase in the electrocatalytic behavior for hydrogen evolution was expected. The most significant factor for the electrocatalytic behavior of Ni-Mo alloys seemed to be the Mo content.

\section{Discussion}

Ni-Mo nanocrystalline electrodeposited alloys containing molybdenum content in the range of 11 to $31 \%$ were produced by changing the applied plating current density from 80 to $5 \mathrm{~mA} / \mathrm{cm}^{2}$. Electrodeposition of Ni-Mo alloys is one of the examples of the induced codeposition mechanism as Mo cannot be electrodeposited alone; however, it could be codeposited like with $\mathrm{Ni}$ or other transitional metals of the iron group [20].

As described by Podlaha and Landolt $[10,11]$ and verified by Zeng et al. [19], codeposition of Ni-Mo takes place on multiple steps as shown in the reactions below:

$$
\begin{aligned}
\mathrm{Ni}(\mathrm{Cit})^{-}+2 \mathrm{e}^{-} \longrightarrow \mathrm{Ni}(\mathrm{s})+(\mathrm{Cit})^{3-} & \\
\mathrm{MoO}^{2-}+\mathrm{Ni}(\mathrm{Cit})^{-}+2 \mathrm{H}_{2} \mathrm{O}+2 \mathrm{e}^{-} \longrightarrow & {\left[\mathrm{Ni}(\mathrm{Cit}) \mathrm{MoO}_{2}\right]_{\mathrm{ads}} } \\
& +4 \mathrm{OH}^{-} \\
{\left[\mathrm{Ni}(\mathrm{Cit}) \mathrm{MoO}_{2}\right]_{\mathrm{ads}}+2 \mathrm{H}_{2} \mathrm{O}+4 \mathrm{e}^{-} \longrightarrow } & \mathrm{Mo}(\mathrm{s})+\mathrm{Ni}(\mathrm{Cit})^{-} \\
& +4 \mathrm{OH}^{-}
\end{aligned}
$$

The mechanism of induced codeposition of molybdenum with nickel involves an adsorbed Ni-Mo reaction intermediate (2). In this case, $\left[\mathrm{Ni}(\mathrm{Cit}) \mathrm{MoO}_{2}\right]_{\text {ads }}$ acts as a surfaceadsorbed intermediate, while citrate acts as a ligand connecting both $\mathrm{Ni}^{2-}$ and $\mathrm{MoO}^{2-}$ together.

By increasing the current density, the reduction rate of $\mathrm{Ni}^{2-}$ ions is increased giving no chance for the surface adsorbed intermediate to be formed, thus, gaining less chance for Mo to be codeposited with $\mathrm{Ni}$, and this leads to a reduction in the Mo content in the Ni-Mo alloys at high current densities [21].

The surface of that nanolayer presented in Figure 1(a) showed microcracks. These cracks could be attributed to the high internal stresses, resulting from higher Mo content in the deposited layers $(31 \% \mathrm{Mo})$, exceeding the equilibrium values at R.T [22]. Another reason for the cracking surface is the hydrogen evolution reaction, which takes place during the electrodeposition process [21].

$\mathrm{X}$-ray diffraction $(\mathrm{XRD})$ patterns for all nanolayers deposited at different current densities exhibited the facecentered-cubic structure of the Ni-Mo solid solution. Samples containing lower Mo content showed XRD patterns of sharpened and less broadened peaks. Those peaks got smaller in height and increased in broadening as the Mo content in the deposited layers increased. These results are in agreement with those of Chassaing et al. $[13,15]$.

The crystallite size of Ni-Mo nanodeposits obtained at (111) XRD peaks was calculated using the Scherer formula. Figure 6 shows the crystallite size of Ni-Mo deposits as a function of the plating current density. A pronounced grain refinement is observed when applying low current density accompanied by a high Mo content $(31 \mathrm{wt} \%)$. These results 


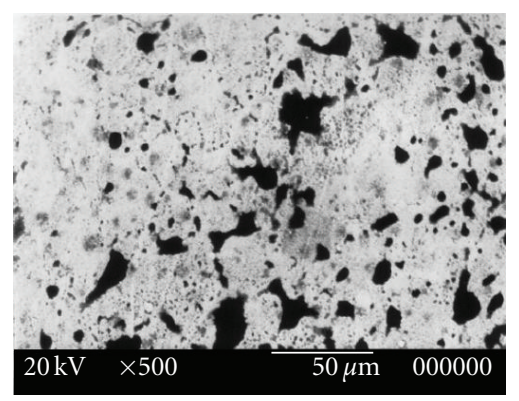

$500 \mathrm{X}$

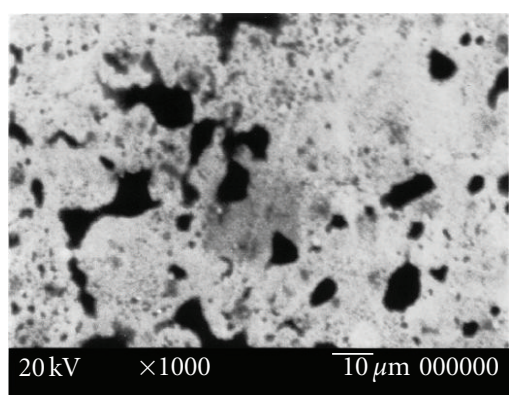

1000X

(a) $31 \% \mathrm{Mo}$

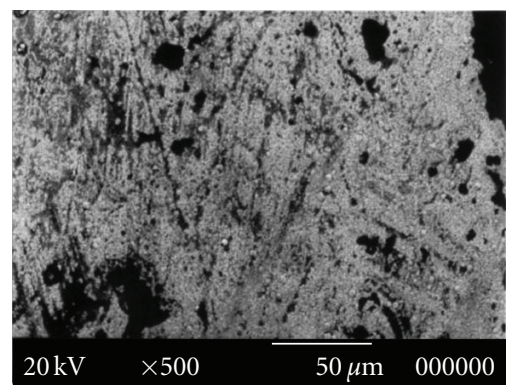

$500 \mathrm{X}$

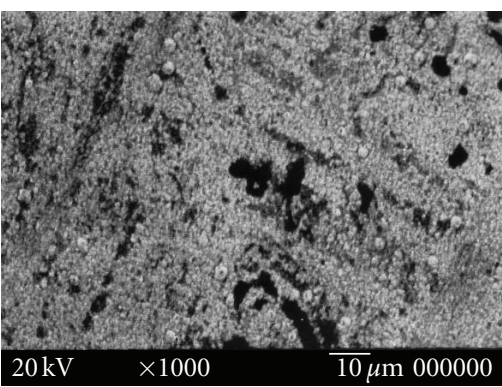

1000X

(b) $23 \% \mathrm{Mo}$

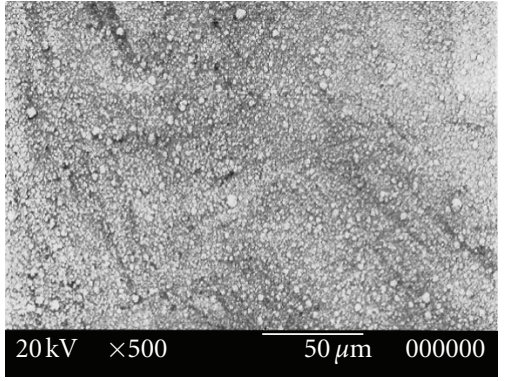

$500 X$

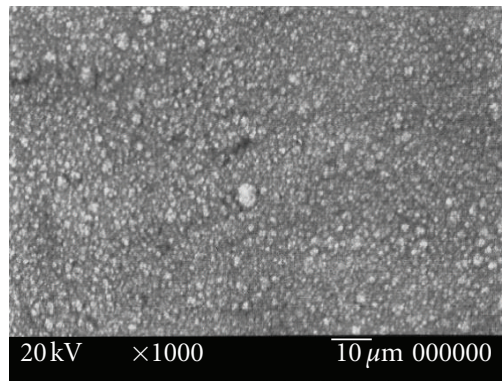

1000X

(c) $15 \% \mathrm{Mo}$

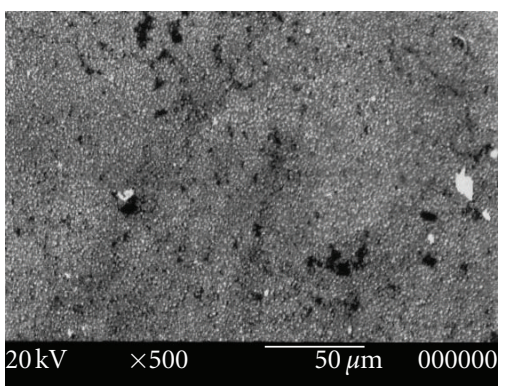

$500 \mathrm{X}$

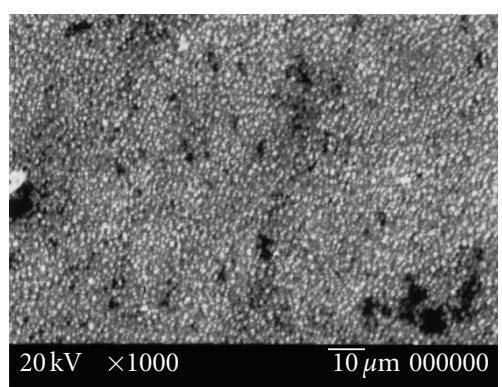

1000X

(d) $11 \% \mathrm{Mo}$

FIGURE 9: SEM micrographs for Ni-Mo nanocrystalline electrodeposits after corrosion in $0.5 \mathrm{M} \mathrm{NaOH}$ solution.

are in agreement with those of Nee et al. [18], who pointed out that the grain size in Ni-Mo deposits is directly related to their composition.

The microhardness of Ni-Mo electrodeposited nanocrystalline alloys is in the range of $174-284 \mathrm{HVN}$. Figure 7 represents a relation between the microhardness values and the crystallite size of Ni-Mo deposits. The hardness values first follow the Hall-Petch equation, where the hardness increases from about 200 to $285 \mathrm{HVN}$ as the crystallite size decreases from $\sim 43$ to $\sim 10 \mathrm{~nm}$. However, at crystallite size less than $\sim 10 \mathrm{~nm}$, the hardness values start to deviate from the Hall-Petch behaviour reaching a hardness of $174 \mathrm{HVN}$ 


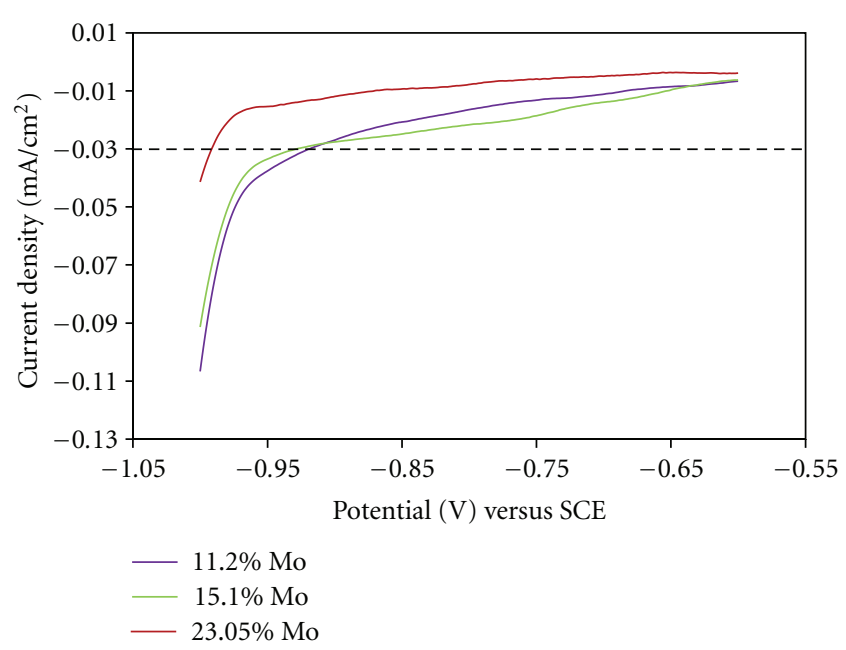

Figure 10: Evans diagrams ( $I-V$ curves) for Ni-Mo nanocrystalline electrodeposits examined in $0.5 \mathrm{M} \mathrm{NaOH}$ solution.

at a crystallite size of $7 \mathrm{~nm}$. This softening phenomenon could be attributed to the high proportion of defect sites, that is, grain boundaries and triple junctions, in the nanocrystalline metals and alloys. The triple junction volume fraction displays greater grain size dependence than the grain boundary volume faction. In the range of 100 to $2 \mathrm{~nm}$, the triple junction volume fraction increases by three orders of magnitude while the grain boundary fraction increases by a little over one order of magnitude, whereby increasing the triple junction content enhances the bulk ductility in polycrystalline materials $[23,24]$.

Nanocrystalline metals and alloys usually experience deterioration while being used for catalytic activities as cathodes for hydrogen production from water electrolysis. Nanocrystalline Ni-Mo electrodeposited alloys were proved to be of more corrosion resistance in $\mathrm{NaOH}$ solution than that of steel substrate as shown in Table 3. The corrosion behaviour for Ni-Mo nanocrystalline alloys was dependent on three contradicting factors: the molybdenum content, surface roughness, and the grain size.

The increase in the Mo content in the Ni-Mo alloys increases the intrinsic corrosion resistance, but it leads to grain size refining. Hence, the fraction of intercrystalline regions increases, which has an opposite deteriorating effect $[21,25]$.

The increase of the intrinsic corrosion resistance of NiMo alloys resulting from the increase of Mo content in the alloys could be due to the formation of oxide film. This film protects the coating from further dissolution, and the higher the Mo content the more stable the oxide film [26].

According to the corrosion results in Table 3, it is shown that the alloy with the highest Mo content records the least negative corrosion potential value $\left(E_{\text {corr }}=-294.2 \mathrm{mV}\right)$, indicating the formation of a stable passive layer compared to the rest of Ni-Mo alloys. However, that alloy recorded the highest corrosion rate $\left(81 \times 10^{-3} \mathrm{~mm} / \mathrm{Y}\right)$ compared to the rest of the Ni-Mo electrodeposited alloys. This high rate of corrosion could be due to the cracks presented in the surface and also due to the fine grains $(7 \mathrm{~nm})$.

At crystallite size $<14 \mathrm{~nm}$, the effect of increasing crystallite size on improving corrosion rate was more pronounced than the effect of reducing Mo content of Ni-Mo deposits. Meanwhile, at crystallite size $>14 \mathrm{~nm}$, the effect of reducing Mo content on increasing corrosion rate was more pronounced than the effect of increasing crystallite size of Ni-Mo nanodeposits. This trend is also being observed in the SEM micrographs of the Ni-Mo nanocrystalline electrodeposited alloys after corrosion shown in Figure 9. The increase in corrosion rate was also attributed to increasing the degree of anisotropy (Figure 4), as well as increasing the surface roughness (Figure 6), resulted from the reduction of Mo content from 31 to $11 \%$ Mo.

According to Sriraman et al. [27], nanocrystalline-nickelbased alloys show high corrosion rates due to the higher grain boundary and triple junction content, which provide sites for electrochemical activity.

The electrocatalytic activity of Ni-Mo nanocrystalline electrodeposited alloys for hydrogen evolution was evaluated by two methods described previously. Both methods confirmed that the Ni-Mo electrodeposited alloy containing $15 \%$ Mo has the lowest potential $(\sim-0.9 \mathrm{~V})$ at a constant current of $-0.04 \mathrm{~mA} / \mathrm{cm}^{2}$, as well as the lowest Tafel slope for cathodic region $(79 \mathrm{mV} / \mathrm{dec})$. The increase of Mo content and the increase of roughness are the main factors for increasing the electrochemical activity of Ni-Mo alloys for HER. This explanation has been demonstrated by Arul Raj and Venkatesan [28], Divisek et al. [29], and Nee et al. [18], who were able to show the exact behaviour of Ni-Mo alloys prepared by different methods. The synergetic effect of NiMo, investigated by Highfield et al. [16], has been ruled out.

The electrocatalytic behaviour for HER being evaluated based on the Tafel slope values was more reliable that taken from the measurements of the over potential values at a constant current density. This is due to the fact that the value of the current density taken here is by far much lower than the current density being employed industrially for hydrogen production from water electrolysis as examined by Krstajić et al. [14].

\section{Conclusions}

(1) Electrodeposition of nodular nanocrystalline Ni-Mo alloys exhibiting one-phase Ni-Mo could be carried out using a bath of nickel sulfate, sodium molybdate, and sodium citrate.

(2) Increasing the applied current density led to a decrease of the molybdenum content in the deposited alloys, increase in crystallite size, and increase of the surface roughness.

(3) The highest microhardness value $(284 \mathrm{Hv})$ corresponded to Ni-Mo nanodeposits with $23 \%$ Mo and crystalline size equal to $10 \mathrm{~nm}$.

(4) The highest corrosion resistance accompanied by relatively high hardness was detected for Ni-Mo electrodeposits containing $15 \%$ Mo. 
(5) The maximum catalytic effect for hydrogen production was obtained for Ni-Mo electrodeposits containing $15 \%$ Mo.

\section{Acknowledgments}

This work was supported by Cairo University Grants for Scientific Research 2010-2011. The authors would like to thank Prof. Mamoun Muhammed, Head of Functional Nano-Materials Division (FNM), The Royal Institute of Technology (KTH), Sweden for providing all the facilities for some samples preparation, SEM and XRD analysis.

\section{References}

[1] R. Schulz, J. Huot, and M. Trudeau, "Nanocrystalline Ni-Mo alloys and their application in electro catalysis," Journal of Materials Science, vol. 9, pp. 2998-3008, 1994.

[2] I. Arul Raj and V. K. Venkatesan, "Characterization of nickelmolybdenum and nickel-molybdenum-iron alloy coatings as cathodes for alkaline water electrolysers," International Journal of Hydrogen Energy, vol. 13, no. 4, pp. 215-223, 1988.

[3] V. Sundaramurthy, A. K. Dalai, and J. Adjaye, "Comparison of P-containing $\gamma-\mathrm{Al}_{2} \mathrm{O}_{3}$ supported Ni-Mo bimetallic carbide, nitride and sulfide catalysts for HDN and HDS of gas oils derived from Athabasca bitumen," Applied Catalysis A, vol. 311, no. 1-2, pp. 155-163, 2006.

[4] T. Borowiecki, W. Gac, and A. Denis, "Effects of small $\mathrm{MoO}_{3}$ additions on the properties of nickel catalysts for the steam reforming of hydrocarbons: III. Reduction of Ni-Mo/ $/ \mathrm{Al}_{2} \mathrm{O}_{3}$ catalysts," Applied Catalysis A, vol. 270, no. 1-2, pp. 27-36, 2004.

[5] J. Z. Huang, Z. Xu, H. L. Li, G. H. Kang, and W. J. Wang, "Effects of sputtering conditions on electrochemical behavior and physical properties of Ni-Mo alloy electrode," Transactions of Nonferrous Metals Society of China, vol. 16, no. 5, pp. 10921096, 2006.

[6] P. Kedzierzawski, D. Oleszak, and M. Janik-Czachor, "Hydrogen evolution on hot and cold consolidated Ni-Mo alloys produced by mechanical alloying," Materials Science and Engineering A, vol. 300, no. 1-2, pp. 105-112, 2001.

[7] R. T. C. Choo, J. M. Toguri, A. M. El-Sherik, and U. Erb, "Mass transfer and electro crystallization analyses of nanocrystalline nickel production by pulse plating," Journal of Applied Electrochemistry, vol. 25, pp. 384-403, 1995.

[8] D. Clark, D. Wood, and U. Erb, "Industrial applications of electrodeposited nanocrystals," Nanostructured Materials, vol. 9, no. 1-8, pp. 755-758, 1997.

[9] E. Chassaing, M. P. Roumegas, and M. F. Trichet, "Electrodeposition of Ni-Mo alloys with pulse reverse potentials," Journal of Applied Electrochemistry, vol. 25, no. 7, pp. 667-670, 1995.

[10] E. J. Podlaha and D. Landolt, "Induced codeposition: I. An experimental investigation of Ni-Mo alloys," Journal of the Electrochemical Society, vol. 143, no. 3, pp. 885-892, 1996.

[11] E. J. Poddlaha and D. Landolt, "Induced codeposition: II. A mathematical model describing the electrodeposition of NiMo alloys," Journal of the Electrochemical Society, vol. 143, no. 3, pp. 893-899, 1996.

[12] L. S. Sanches, S. H. Domingues, C. E. B. Marino, and L. H. Mascaro, "Characterisation of electrochemically deposited NiMo alloy coatings," Electrochemistry Communications, vol. 6, no. 6, pp. 543-548, 2004.
[13] M. Donten, H. Cesiulis, and Z. Stojek, "Electrodeposition of amorphous/nanocrystalline and polycrystalline Ni-Mo alloys from pyrophosphate baths," Electrochimica Acta, vol. 50, no. 6, pp. 1405-1412, 2005.

[14] N. V. Krstajić, V. D. Jović, L. Gajić-Krstajić, B. M. Jović, A. L. Antozzi, and G. N. Martelli, "Electrodeposition of Ni-Mo alloy coatings and their characterization as cathodes for hydrogen evolution in sodium hydroxide solution," International Journal of Hydrogen Energy, vol. 33, no. 14, pp. 3676-3687, 2008.

[15] E. Chassaing, N. Portail, A. F. Levy, and G. Wang, "Characterisation of electrodeposited nanocrystalline Ni-Mo alloys," Journal of Applied Electrochemistry, vol. 34, no. 11, pp. 10851091, 2004.

[16] J. G. Highfield, E. Claude, and K. Oguro, "Electrocatalytic synergism in $\mathrm{Ni} / \mathrm{Mo}$ cathodes for hydrogen evolution in acid medium: a new model," Electrochimica Acta, vol. 44, no. 16, pp. 2805-2814, 1999.

[17] J. M. Jakšić, M. V. Vojnović, and N. V. Krstajić, "Kinetic analysis of hydrogen evolution at Ni-Mo alloy electrodes," Electrochimica Acta, vol. 45, no. 25-26, pp. 4151-4158, 2000.

[18] C. C. Nee, W. Kim, and R. Weil, "Pulsed electrodeposition of Ni-Mo alloys," Journal of the Electrochemical Society, vol. 135, no. 5, pp. 1100-1103, 1988.

[19] Y. Zeng, Z. Li, M. Ma, and S. Zhou, "In situ surface Raman study of the induced codeposition mechanism of Ni-Mo alloys," Electrochemistry Communications, vol. 2, no. 1, pp. 3638, 2000.

[20] A. Brenner, Electrodeposition of Alloys, vol. 1, chapter 1, Academic Press, New York, NY, USA, 1963.

[21] E. Chassaing, K. Vu Quang, and R. Wiart, "Mechanism of nickel-molybdenum alloy electrodeposition in citrate electrolytes," Journal of Applied Electrochemistry, vol. 19, no. 6, pp. 839-844, 1989.

[22] ASM Metals Handbook and ASM International, Alloy Phase Diagrams, vol. 3, 1992.

[23] U. Erb, A. M. El-Sherik, G. Palumbo, and K. T. Aust, "Synthesis, structure and properties of electroplated nanocrystalline materials," Nanostructured Materials, vol. 2, no. 4, pp. 383390, 1993.

[24] T. Yamasaki, P. Schloßmacher, K. Ehrlich, and Y. Ogino, "Formation of amorphous electrodeposited Ni-W alloys and their nanocrystallization," Nanostructured Materials, vol. 10, no. 3, pp. 375-388, 1998.

[25] P. Prioteasa, L. Anicǎi, and T. Vişan, "Synthesis and corrosion characterization of electrodeposited Ni-Mo alloys obtained from aqueous solutions," UPB Scientific Bulletin, Series B, vol. 72, no. 4, pp. 11-24, 2010.

[26] E. Navarro-Flores, Z. Chong, and S. Omanovic, "Characterization of $\mathrm{Ni}, \mathrm{NiMo}, \mathrm{NiW}$ and NiFe electroactive coatings as electrocatalysts for hydrogen evolution in an acidic medium," Journal of Molecular Catalysis A, vol. 226, no. 2, pp. 179-197, 2005.

[27] K. R. Sriraman, S. Ganesh Sundara Raman, and S. K. Seshadri, "Corrosion behaviour of electrodeposited nanocrystalline Ni$\mathrm{W}$ and Ni-Fe-W alloys," Materials Science and Engineering A, vol. 460-461, pp. 39-45, 2007.

[28] I. Arul Raj and V. K. Venkatesan, "Characterization of nickelmolybdenum and nickel-molybdenum-iron alloy coatings as cathodes for alkaline water electrolysers," International Journal of Hydrogen Energy, vol. 13, no. 4, pp. 215-223, 1988.

[29] J. Divisek, H. Schmitz, and J. Balej, "Ni and Mo coatings as hydrogen cathodes," Journal of Applied Electrochemistry, vol. 19, no. 4, pp. 519-530, 1989. 

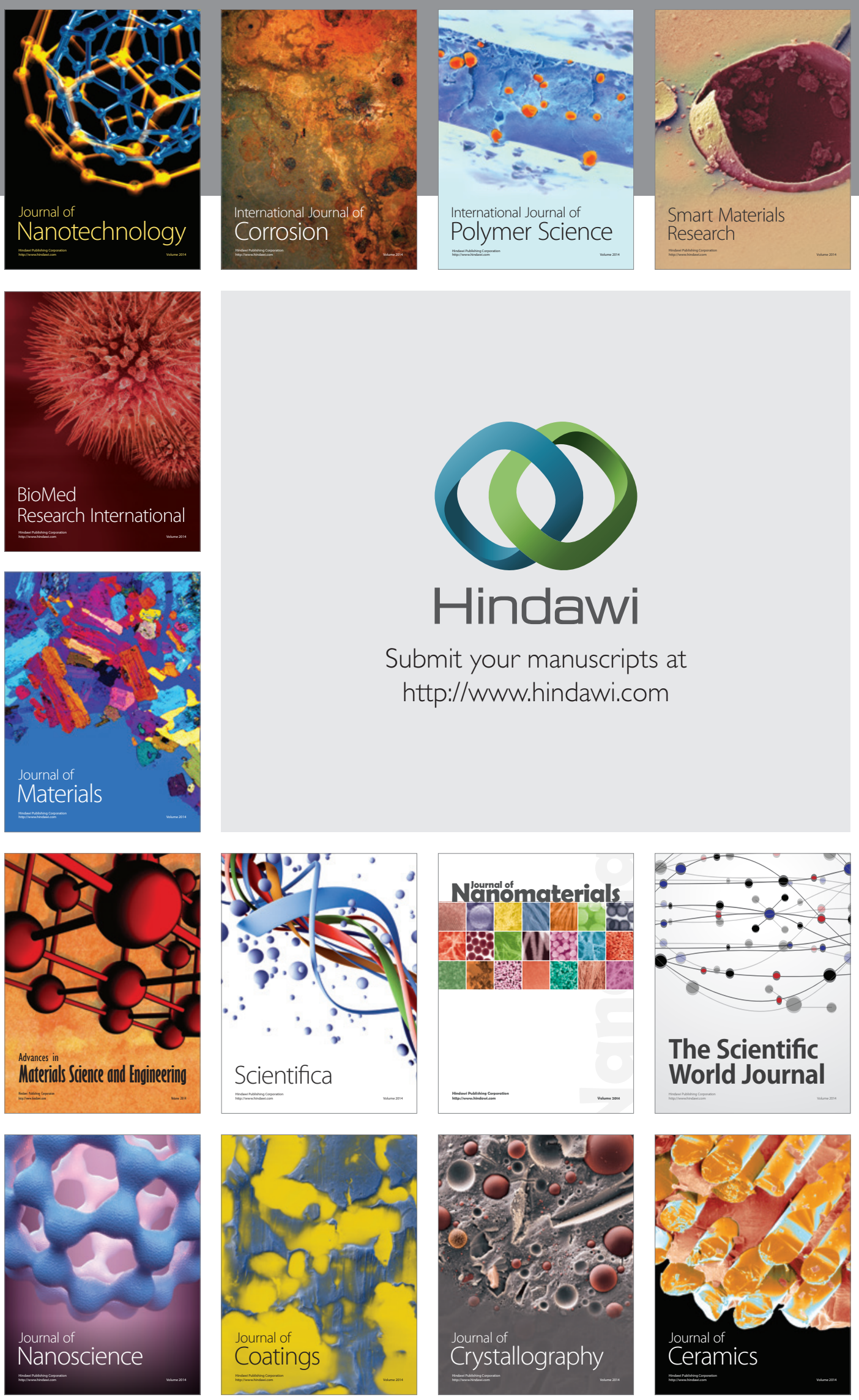

The Scientific World Journal

Submit your manuscripts at

http://www.hindawi.com

\section{World Journal}

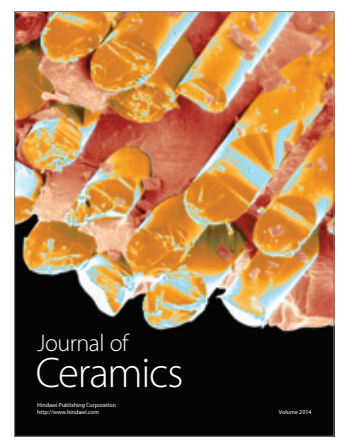

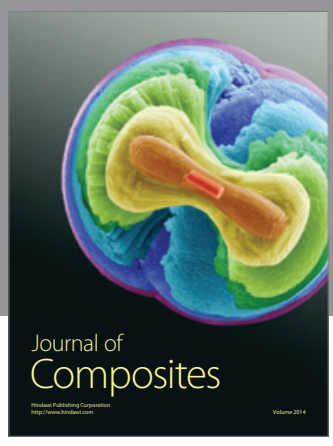
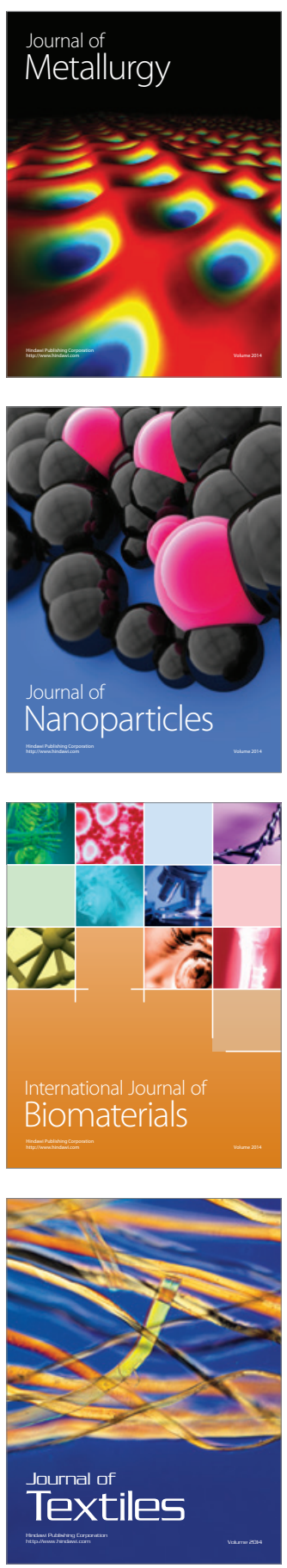